\title{
Absceso hepático
}

Diversidad de opiniones - Triunfo del diagnóstico - Operación y curación

\section{Por el doctor Andrés Gómez de Bucaramanga}

En el mes de Abril del año próximo pasado de 1909, fuimos consultados por un joven (I.C.M.) de distinguida familia, como de veintiún años de edad, á quien habíamos recetado un año antes, poco más ó menos, para una disentería primero, y algunos meses más tarde para unas hemorroides internas, enfermedades que cedieron á los tratamientos ordenados, y permitieron al paciente viajar á la capital de la República, de donde regresó en completo estado de salud y bastante robusto.

Cuanto el enfermo volvió á nuestro consultorio, sufría fiebres vesperales, inapetencia, insomnio, dolores vagos en los hipocondrios, meteorismo; tenía la lengua pastosa, aumentado el volumen del hígado y del bazo, pulso frecuente, orina turbia y sedimentosa. Como la fiebre fuera casi siempre precedida de calofríos más ó menos intensos y se terminara por sudores en el curso de la noche, nos inclinamos á creer que se trataba de un paludismo, enfermedad que había sufrido antes el paciente y que es común en estas regiones donde abundan los mosquitos.

Fracasado el tratamiento específico que impusimos por algunos días, y visto que los dolores se localizaron en el hipocondrio derecho, y el hígado aumentaba de volumen, y teniendo además el antecedente patológico de la disentería anterior, no vacilamos en determinarnos á diagnosticar una hepatitis supurada, a implantar un régimen enérgico y a proponer poco después una intervención quirúrgica, que por entonces no fue aceptada.

El temor natural del paciente y de su familia para someterse á una operación, indispensable pero peligrosa, lo llevó al consultorio de varios facultativos ninguno de los cuales estuvo de acuerdo con nuestra opinión. Cada uno de ellos fue estableciendo el tratamiento apropiado a la entidad mórbida y que creía haber encontrado, y nuestro cliente fue tratado hasta fines de Agosto del mismo año como pleurítico, palúdico y tuberculoso del pulmón derecho.

El último de los colegas que lo estuvo tratando, como si sufriera apenas de una hipertrofia hepática de origen palúdico con manifestaciones febriles vesperales, resolvió aconsejarle un clima frío y seco, con las correspondientes indicaciones á su estado patológico.

Fueron ningunas las mejorías ó ventajas que nuestro paciente pudo apreciar con el cambio de clima y el tratamiento impuesto; antes bien, sentía decaer sus fuerzas más y más, y que el estado de su enfermedad, lejos de retroceder, avanzaba, motivo por el cual resolvió abandonar el temperamento y volver al seno de su familia. 
A fines de Agosto del mismo año, los dolientes más aproximados é interesados por la salud de nuestro enfermo, nos suplicaron volviéramos á encargarnos de él, y resolviéramos en definitiva lo que mejor pudiera convenir para salvarle la vida que ya parecía en peligro inminente. No faltaron las excusas por el abandono en que se nos había dejado para consultar otras muchas opiniones, pretextando el natural recelo para resolverse á una operación indispensable quizá, pero de resultados al fin problemáticos ó eventuales.

Debido á la posición y al carácter de los interesados, no pudimos esquivar nuestra aceptación, y volvimos á examinar nuestro antiguo cliente, á quien todos habíamos visto por las calles de la ciudad flaco, pálido, cabizbajo, marchando con pasos lentos, meditabundo, tosiendo de cuando en cuando y comprimiendo con el antebrazo derecho el hipocondrio del mismo lado.

Encontramos el volumen del hígado más aumentado que al principio, muy sensible á la percusión, ligero edema intercostal, y apenas apreciable la circulación colateral de la región. El enflaquecimiento era extremo, el pulso débil latía 100 y 110 veces por minuto; había anorexia, fiebre vesperal, orina rojiza, escasa, dolores nocturnos hepáticos, meteorismo, constipación, sudores.

Como el terror á la operación existía aún más intenso, y como las dudas y vacilaciones sobre nuestro diagnóstico desempeñaban en su espíritu un papel importante debido á todos los pareceres que había escuchado, y á los cuales había estado sometido, no se resolvía nuestro enfermo á la intervención quirúrgica, por lo cual tuvimos que apelar á una punción profunda como último recurso que nos quedaba, y mostrarle el pus que llevaba en su organismo. Ante semejante argumento se sometió resueltamente á la intervención.

Durante algunos días estuvimos preparando nuestro enfermo, pues era bien alarmante el estado de miseria fisiológica en que se hallaba: aumentamos y regularizamos la energía cardíaca, provocamos los movimientos peristálticos del intestino, com- batimos el meteorismo, la anorexia y la fiebre, desinfectamos el aparato digestivo.

Al fin llegó el 10 de Septiembre del mismo año, día fijado para la operación, á las ocho de la mañana.

En asocio de nuestros colegas y amigos los doctores Gregorio Consuegra y Emilio Villamizar (q.e.p.d.), llevamos al paciente á la mesa de operación, después de haberle puesto una inyección de morfina y esparteína para calmar el estado nervioso que era alarmante y asegurar contra la acción del cloroformo el ritmo y la fuerza del corazón en un organismo ya tan decaído.

Llevada la anestesia general hasta el sueño profundo y hecha la asepsia del campo operatorio, resolvimos proceder por la vía intercostal, pues el absceso estaba situado profundamente en la convexidad hepática y comprimía bastante hacia arriba el pulmón derecho.

Hicimos dos pequeñas incisiones transversarles sobre la octava costilla, á una distancia de cinco centímetros, hacia la parte media y las reunimos por una longitudinal sobre la cara externa de la misma costilla; disecamos el periosto, é hicimos la resección de la parte media de dicho hueso, en una extensión de siete centímetros.

Al hacer la incisión sobre el hígado suturamos, con catgut, en la parte inferior, la pleura diafragmática á la pleura costal, por no existir en ese punto adherencia ninguna; á pesar de la edad del absceso, un trócar nos sirvió de guía para llegar hasta el foco, el cual abrimos ampliamente; una onda de pus rojizo inundó el campo operatorio y pudimos apreciar la cantidad de este líquido en unos 1,500 gramos, poco más ó menos. La superficie interna del foco era un extremo anfractuosa; por la percusión notamos que el pulmón derecho adquirió sus limites naturales y funcionaba con toda amplitud. Lavamos abundantemente con agua hervida adicionada, con creolina y ácido fénico, pusimos en el foco un tubo grueso de caucho, cubrimos con algodón al sublimado é hidrófilo, luégo efectuamos una compresa y el 
vendaje. Por la noche se cambiaron los algodones sin mover el tubo y sin lavado.

Al día siguiente dos lavados en las veinticuatro horas, inyección diaria de arrhenal, píldoras de Easton, vino de quina y kola, alimentación abundante, desinfectantes gastro-intestinales.

Desde la primera noche desapareció la fiebre, cesaron los dolores y el pulso bajó á 80 por minuto; durante algunos días la orina permaneció turbia, abundante, cargada de fosfatos y pigmentos biliares.

Como la supuración fuera disminuyendo diariamente y ni una sola vez presentara alteraciones de ninguna clase, se hizo apenas una lavado diario desde el duodécimo día en adelante. A medida que la cicatrización avanzaba, el estado general mejoraba visiblemente; el tubo de drenage fue cambiándose por otros de menor calibre, y al mes y medio se retiró definitivamente, y la pequeña herida que quedaba cerró en pocos días.

Nuestro operado está hoy entregado á sus ocupaciones y más robusto que en ninguna otra época de su vida. Hemos tenido, pues, la satisfacción de devolver por medio de la Cirugía un miembro útil á la sociedad, á lo cual contribuyó, en gran parte, los cuidados constantes pre y post operatorios.

\section{Comentario}

\author{
Dra. Adriana Córdoba \\ Cirujana General Universidad del Rosario \\ Cirujana Hospital de San José
}

El Dr. Andrés Gómez nos hace la descripción de la Historia Clínica de un paciente de 21 años manejado en 1909 en quien por los datos obtenidos se le diagnosticó un absceso hepático indicándole tratamiento quirúrgico el cual se le aplicó al enfermo. Sin embargo el paciente fue tratado inicialmente como un paludismo sin presentar mejoría y ante esta propuesta el paciente rechaza el procedimiento. Va en busca de otras opiniones y se le practican otros tratamientos sin mejoría. Al ver que su estado seguía en deterioro consultó nuevamente a su primer médico y aceptó el tratamiento propuesto por este, se le practica drenaje del absceso hepático además de tratamiento médico con éxito y mejoría del paciente.

Vemos que a pesar de que la clínica nos llevó a un diagnóstico correcto el paciente no aceptó el tratamiento seguramente en parte por las condiciones en que se practicaban las cirugías en esa época, el miedo del paciente ante cualquier intervención quirúrgica y seguramente a que no se disponía de métodos diag- nósticos que nos permitieran tener más certeza en el diagnóstico.

En la actualidad el diagnóstico de absceso hepático ha evolucionado y además de la clínica tan útil contamos con la ultrasonografía, un método de fácil disponibilidad, no invasivo y con una alta sensibilidad y especificidad en el diagnóstico de esta patología, con el único inconveniente que es operador dependiente y que en algunas etapas de la enfermedad en que absceso hepático es isodenso con el tejido normal se dificulta el diagnóstico. Además el tratamiento quirúrgico de esta patología ha cambiado sustancialmente llevándonos casi a no hacer intervenciones de este tipo para el manejo de las complicaciones ya que el drenaje percutáneo guiado por TAC o por ecografía ha mostrado muy buenos resultados y ha reemplazado a la cirugía abierta en el manejo de estos pacientes. También es importante resaltar el manejo médico que en algunas ocasiones es el único tratamiento para resolver esta patología. 